\title{
Taking the pulse of a sick kidney: Arterial stiffness in glomerulonephritis
}

\author{
Anke Doyon • Franz Schaefer
}

Received: 4 November 2010 /Revised: 13 November 2010 / Accepted: 16 November 2010 /Published online: 11 December 2010

(C) IPNA 2010

\begin{abstract}
Arterial stiffness is an increasingly recognized independent predictor of cardiovascular morbidity. Vessel volume and wall texture are the main determinants of pulse wave velocity (PWV), the most commonly used indicator of arterial elasticity. Hence, measurements of PWV will be affected by the site of measurement and the overall dimensions of the vascular tree as well as by alterations of vascular morphology. In children, methodological heterogeneity and the lack of pediatric reference values complicate the interpretation of PWV. Arterial elasticity is altered in numerous clinical conditions such as vasculitis, end-stage renal disease, and diabetes. Novel evidence suggests that acute postinfectious glomerulonephritis, but not pyelonephritis, is also associated with increased arterial stiffness, the persistence of which may predict the emergence of chronic kidney disease. We review the potential mechanisms underlying the link between acute and chronic kidney disease and impaired arterial elasticity. These might include activation of the renin-angiotensin system, sympathetic hyperactivation, and a subclinical state of inflammation. In view of the excessive cardiovascular comorbidity associated with kidney disease, the increasing evidence of the prognostic relevance of arterial stiffness should encourage further research investigating the usefulness of PWV as a biomarker in acute and chronic kidney disorders.
\end{abstract}

Keywords Pulse wave velocity - Arterial stiffness . Post-streptococcal glomerulonephritis · Inflammation · Hyperadrenergic state $\cdot$ Cardiovascular prognosis

\footnotetext{
A. Doyon $\cdot$ F. Schaefer $(\bowtie)$

Division of Pediatric Nephrology, Center for Pediatrics and Adolescent Medicine, University of Heidelberg, Im Neuenheimer Feld 430,

69120 Heidelberg, Germany

e-mail: franz.schaefer@med.uni-heidelberg.de
}

In this issue of the journal, Yu et al. [1] report their finding of an increased brachial-ankle pulse wave velocity (baPWV) in children with acute post-streptococcal glomerulonephritis (APSGN). They interpret this phenomenon as reflective of a state of inflammation affecting systemic arterial function and speculate about the potential prognostic relevance of a prolonged increase baPWV after APSGN. Notably, similar changes were not found in children with acute bacterial pyelonephritis. The finding that changes of arterial function are present outside the kidney in APSGN is an interesting observation that deserves further attention.

\section{Clinical relevance of PWV}

Vascular physiologists consider pulse wave velocity (PWV) a reliable measure of arterial stiffness [2]. PWV has recently become a focus of interest in a number of clinical conditions where functional and morphological alterations of the arterial tree are of prognostic relevance. Consistent changes in PWV have been observed in children and adults with end-stage renal disease [3-7], diabetes mellitus [8, 9], and vasculitis [10-12]. Arterial stiffness has been attributed independent prognostic significance. Increased PWV predicts cardiovascular morbidity and mortality in patients with hypertension, end-stage renal disease, diabetes, old age, and even in the general population $[13,14]$.

\section{Principles of arterial mechanics}

To understand how changes in the texture of the arterial tree lead to an increased arterial stiffness measurable by alterations in pulse wave velocity, it is essential to review 
some basic principles in arterial mechanics and to have a closer look at the measurement techniques.

The propagation model of the arterial system assumes that there is an increase in stiffness along the vessel tree depending on the vessel composition, diameter, and wall thickness. In this model, the speed of a pulse wave traveling along the arterial tree can be described by the relationship between a change in pressure and the resultant change in vessel volume $\left(\mathrm{c} 0=\sqrt{ }\left(\mathrm{V}^{*} \Delta \mathrm{P} / \mathrm{p}^{*} \Delta \mathrm{V}\right)\right.$ [15]. A highly distensible vessel will react with a greater volume change at a given pressure, resulting in a lower pulse wave speed.

Pulse waves are recorded at two distinct sites of the body and the time delay is related to the covered distance between those two sites $(\mathrm{Vp}=\Delta \mathrm{D} / \Delta \mathrm{T})$.

Due to the varying distensibility of arteries along the arterial tree PWV, measurements must take into account the site of examination. According to expert consensus [2], aortic pulse wave velocity (aoPWV) is considered the gold standard to evaluate central arterial stiffness. Brachial-ankle PWV measurements are predominantly used in Asian countries, as in the study by $\mathrm{Yu}$ et al. While correlation studies have shown that baPWV provides comparable information as aortic PWV [16], it should be noted that baPWV covers more peripheral arteries including segments of the arms and legs resulting in systematically higher velocity than aoPWV [17]. At any rate, the information provided by $\mathrm{Yu}$ et al. is internally consistent since baPWV was used in patients and controls.

\section{Measurement techniques}

Pulse waves can be recorded by different techniques, including Doppler sonography, applanation tonometry, oscillometry, and even magnetic resonance imaging (MRI) techniques. The Collin-Omron device used by $\mathrm{Yu}$ et al. is an oscillometric instrument. In pediatrics, oscillometric measurements appear most appropriate because children will more likely accept a procedure resembling a blood pressure reading than a procedure that requires a direct pressure application over an artery or lying still in an MRI tomograph for considerable time. Recently, several oscillometric devices for the measurement of pulse wave velocity have been developed and applied in the pediatric environment, among them the Collin-Omron device measuring baPWV, the Arteriograph and the Vicorder evaluating carotid-femoral pulse wave velocity. At the present time, all of these techniques await stringent validation and cross-validation in children. Moreover, while PWV appears to increase substantially with body growth during childhood, reference data sets remain to be established in healthy children.

\section{Mechanistic links of PWV to acute and chronic disease}

The finding that systemic PWV is increased in an acute disorder apparently limited to the kidneys is intriguing. The authors interpret the increased baPWV as a result of systemic inflammation leading to arterial wall changes.

Both increased aortic and baPWV have been linked to states of general inflammation in recent studies. In Familial Mediterranean Fever [12], and even after resolved vasculitis in Kawasaki's disease, elevated baPWV is present [18]. Andoh et al. [19] found a correlation between baPWV and high sensitivity C-reactive protein (hs-CRP) in Japanese men. Aortic PWV has been shown to be increased in ANCA-associated systemic vasculitis [10] and rheumatoid arthritis [20]. However, it is not readily evident why ASPGN, a localized glomerular disease, should be associated with comparable abnormalities of the arterial tree as these systematic inflammatory disorders. To underline the conclusion that systemic inflammation is the underlying process for the observed baPWV changes in APSGN, it would have been helpful to correlate inflammation markers such as CRP with the baPWV results.

An alternative explanations of the observed findings should be considered. During the acute phase of APSGN, blood pressure is significantly increased, compared to both healthy controls and children with acute pyelonephritis. Hypertension can influence pulse wave velocity [21]. Hypertension in ASPGN may be caused by volume overload, activation of the renin-angiotensin system, and sympathetic hyperactivity [22]. Kidney dysfunction has been generally linked to a hyperadrenergic state via stimulation of intrarenal afferent autonomous neurons and impaired catecholamine degradation by the kidneyspecific enzyme renalase [23, 24]. An increased vascular tone mediated by neural and/or humoral mechanisms might constitute a direct pathophysiological link between acute kidney injury and increased arterial stiffness.

\section{Prognostic relevance of PWV}

The findings of $\mathrm{Yu}$ et al. also highlight the potential prognostic value of a persistently increased PWV with regards to the progression of APSGN to chronic renal disease. Two of the observed children progressed to chronic kidney failure and one of them to end-stage renal disease. In both children, baPWV did not normalize. Therefore, the continuous elevation of PWV appeared to be predictive of the renal outcome, whereas laboratory markers such as hypocomplementemia and antistreptolysin titers were not. PWV has been shown to be increased in chronic kidney disease [3-7], and the observation of $\mathrm{Yu}$ et al. might simply reflect chronic kidney disease 
without any specificity for the underlying disorder. In addition, persistently elevated blood pressure might have confounded the association.

Notwithstanding our incomplete mechanistic understanding, it is of interest that arterial stiffness was persistently altered in the few exceptional cases of APSGN turning from acute into chronic kidney disease. If PWV alteration during acute kidney injury proves to be predictive for long-term renal outcome, oscillometric PWV monitoring could become a valuable biomarker in clinical practice.

\section{Perspectives}

In conclusion, the study of $\mathrm{Yu}$ et al. is of considerable interest and should stimulate further vascular research using easily applicable non-invasive technology in children with acute and chronic kidney disorders. Such research, which should be performed in a variety of underlying renal diseases, should clarify the sensitivity and reliability of different PWV technologies in identifying ongoing or imminent cardiovascular disease and renal disease progression in children, relative to established clinical, anthropometric, and biochemical disease markers. If successful, these studies could lead the way to implementing PWV measurements in clinical practice as a useful adjunct to current cardiovascular monitoring routines.

\section{References}

1. Yu MC, Yu MS, Yu MK, Lee F, Huang WH (2010) Acute reversible changes of brachial-ankle pulse wave velocity in children with acute poststreptococcal glomerulonephritis. Pediatr Nephrol. doi:10.1007/s00467-010-1590-2

2. Laurent S, Cockcroft J, Van Bortel L, Boutouyrie P, Giannattasio C, Hayoz D, Pannier B, Vlachopoulos C, Wilkinson I, StruijkerBoudier H, European Network for Non-invasive Investigation of Large Arteries (2006) Expert consensus document on arterial stiffness: methodological issues and clinical applications. Eur Heart J 27:2588-2605

3. Mourad JJ, Pannier B, Blacher J, Rudnichi A, Benetos A, London GM, Safar ME (2001) Creatinine clearance, pulse wave velocity, carotid compliance and essential hypertension. Kidney Int 59:1834-1841

4. Wang MC, Tsai WC, Chen JY, Huang JJ (2005) Stepwise increase in arterial stiffness corresponding with the stages of chronic kidney disease. Am J Kidney Dis 45:494-501

5. Covic A (2006) Increased arterial stiffness in children on haemodialysis. Nephrol Dial Transplant 21:729-735

6. Shroff RC, Donald AE, Hiorns MP, Watson A, Feather S, Milford D, Ellins EA, Storry C, Ridout D, Deanfield J, Rees L (2007) Mineral metabolism and vascular damage in children on dialysis. J Am Soc Nephrol 18:2996-3003

7. Kis E, Cseprekál O, Horváth Z, Katona G, Fekete BC, Hrapka E, Szabó A, Szabó AJ, Fekete A, Reusz GS (2008) Pulse wave velocity in end-stage renal disease: influence of age and body dimensions. Pediatr Res 63:95-98

8. Heilman K, Zilmer M, Zilmer K, Lintrop M, Kampus P, Kals J, Tillmann V (2009) Arterial stiffness, carotid artery intima-media thickness and plasma myeloperoxidase level in children with type 1 diabetes. Diab Res Clin Pract 84:168-173

9. Haller MJ, Samyn M, Nichols WW, Brusko T, Wasserfall C, Schwartz RF, Atkinson M, Shuster JJ, Pierce GL, Silverstein JH (2004) Radial artery tonometry demonstrates arterial stiffness in children with type 1 diabetes. Diab Care 27:2911-2917

10. Booth AD, Wallace S, McEniery CM, Yasmin BJ, Jayne DRW, Wilkinson IB (2004) Inflammation and arterial stiffness in systemic vasculitis: a model of vascular inflammation. Arthritis Rheum 50:581-588

11. Cheung YF, Brogan PA, Pilla CB, Dillon MJ, Redington AN (2002) Arterial distensibility in children and teenagers: normal evolution and the effect of childhood vasculitis. Arch Dis Child 87:348-351

12. Yildiz M, Masatlioglu S, Seymen P, Aytac E, Sahin B, Seymen HO (2006) The carotid-femoral (aortic) pulse wave velocity as a marker of arterial stiffness in Familial Mediterranean Fever. Can J Cardiol 22:1127-1131

13. Meaume S, Benetos A, Henry OF, Rudnichi A, Safar ME (2001) Aortic pulse wave velocity predicts cardiovascular mortality in subjects >70years of age. Arterioscler Thromb Vasc Biol 21:2046-2050

14. Hansen TW, Li Y, Staessen JA, Jeppesen J, Rasmussen S, Wang JG, Thijs L, Ibsen H, Safar ME, Torp-Pedersen C (2008) Independent prognostic value of the ambulatory arterial stiffness index and aortic pulse wave velocity in a general population. $\mathrm{J}$ Hum Hypertens 22:214-216

15. Bramwell JC, Hill AV (1922) The velocity of the pulsewave in man. Proc R Soc Lond Biol 93:298-306

16. Tsuchikura S, Shoji T, Kimoto E, Shinohara K, Hatsuda S, Koyama H, Emoto M, Nishizawa Y (2010) Brachial-ankle pulse wave velocity as an index of central arterial stiffness. J Atheroscler Thromb 17:658-665

17. Tanaka H, Munakata M, Kawano Y, Ohishi M, Shoji T, Sugawara J, Tomiyama H, Yamashina A, Yasuda H, Sawayama T, Ozawa T (2009) Comparison between carotid-femoral and brachial-ankle pulse wave velocity as measures of arterial stiffness. J Hypertens 27:2022-2027

18. Cheung YF, Yung TC, Tam SCF, Ho MHK, Chau AKT (2004) Novel and traditional cardiovascular risk factors in children after Kawasaki disease: implications for premature atherosclerosis. J Am Coll Cardiol 43:120-124

19. Andoh N, Minami J, Ishimitsu T, Ohrui M, Matsuoka H (2006) Relationship between markers of inflammation and brachial-ankle pulse wave velocity in Japanese men. Int Heart J 47:409-420

20. Mäki-Petäjä KM, Hall FC, Booth AD, Wallace SML, Yasmin Bearcroft PWP, Harish S, Furlong A, McEniery CM, Brown J, Wilkinson IB (2006) Rheumatoid arthritis is associated with increased aortic pulse-wave velocity, which is reduced by antitumor necrosis factor-alpha therapy. Circulation 114:1185-1192

21. Stewart AD, Millasseau SC, Kearney MT, Ritter JM, Chowienczyk PJ (2003) Effects of inhibition of basal nitric oxide synthesis on carotid-femoral pulse wave velocity and augmentation index in humans. Hypertension 42:915-918

22. Schlaich MP, Socratous F, Hennebry S, Eikelis N, Lambert EA, Straznicky N, Esler MD, Lambert GW (2009) Sympathetic activation in chronic renal failure. J Am Soc Nephrol 20:933-939

23. Li G, Xu J, Wang P, Velazquez H, Li Y, Wu Y, Desir GV (2008) Catecholamines regulate the activity, secretion, and synthesis of renalase. Circulation 117:1277-1282

24. Xu J, Li G, Wang P, Velazquez H, Yao X, Li Y, Wu Y, Peixoto A, Crowley S, Desir GV (2005) Renalase is a novel, soluble monoamine oxidase that regulates cardiac function and blood pressure. J Clin Invest 115:1275-1280 